\title{
Urban and Rural HIV Estimates among Adult Population (15 - 49 Years) in Selected States of India Using Spectrum Data
}

\author{
Lincoln Priyadarshi Choudhury'1, Jayaraman Prabakaran² \\ ${ }^{1}$ Guwahati, India \\ ${ }^{2}$ Tamil Nadu State AIDS Control Society (TANSACS), Chennai, India \\ Email: lincolnchoudhury@gmail.com, prabakarandrnaco@gmail.com
}

Received 20 August 2015; accepted 22 September 2015; published 25 September 2015

Copyright (C) 2015 by authors and Scientific Research Publishing Inc.

This work is licensed under the Creative Commons Attribution International License (CC BY). http://creativecommons.org/licenses/by/4.0/

(c) (i) Open Access

\section{Abstract}

HIV estimation has become a standard tool for understanding the epidemic. Although the majority of India's population lives in rural areas, to date, an exploration of the urban and rural HIV epidemic has not been undertaken. The objective of this study is to develop HIV estimation based on urban and rural adult populations in selected states of India to understand the difference in HIV related indices geographically. Ten states were selected based on HIV prevalence levels-Andhra Pradesh, Tamil Nadu, Karnataka, Maharashtra, Manipur, and Nagaland, Mizoram, Punjab, Odisha and Jharkhand. Spectrum, version 4.53 beta 19, was used. Data files of Indian national estimation, 2010-11 which included population, HIV Sentinel Surveillance, Integrated Bio Behavioral Assessment and program coverage data, were used and alterations made wherever necessary. The urban and rural sub epidemic structures and their subpopulations were separately configured in the Estimation projection package and curve fitting done. Outputs for each state were separately analyzed. Findings show that HIV prevalence is lower in urban than rural areas in Tamil Nadu and Maharashtra; in Karnataka there is no difference in HIV prevalence in the urban and rural populations; and in the remaining seven states urban HIV prevalence is higher as compared to rural HIV prevalence. In the states of Andhra Pradesh, Tamil Nadu, Maharashtra, Odisha and Punjab, the number of people living with HIV, new HIV infections and deaths among people living with HIV is higher in the rural than in the urban population. An early and lower peak in HIV prevalence and incidence in the urban population was seen in Andhra Pradesh, Tamil Nadu, Karnataka and Nagaland, while in Maharashtra the rural peak was earlier and higher. Mizoram shows an earlier and lower peak in the rural population while Manipur shows an earlier and higher urban peak. In Odisha, the epidemic peaked earlier and was lower in the rural than the urban population. HIV prevalence in the urban population in Punjab was still peaking while HIV incidence was earlier and lower in the rural population. In Jharkhand, both urban and rural HIV prevalence and incidence are still increasing. Our findings indicate lower levels of HIV prevalence and incidence in the 
urban population as compared to the rural populations in Maharashtra and Tamil Nadu. In the remaining eight states, urban prevalence and incidence are higher than their rural counterparts. Future estimations of the HIV epidemic in the country need to adopt a similar approach to inform the design of appropriate state-level strategies for HIV prevention in urban and rural areas.

\title{
Keywords
}

\author{
HIV Sentinel Surveillance, HIV Estimation, HIV Prevalence, HIV Incidence, High Risk Group, \\ Biological Behavioral Assessment
}

\section{Introduction}

Global estimates indicate a declining number of new HIV infections in most parts of the world, including India [1]. While there is a recent publication by Joint United Nations Programme on HIV/AIDS (UNAIDS) on the HIV epidemic in selected cities, [2] global information on the rural HIV epidemic is limited. HIV estimations for urban and rural areas have been separately undertaken in some high HIV prevalence countries like Ethiopia and Rwanda at the national level [3]. In 2003, while Rwanda reported high (13.2\%) but declining urban HIV prevalence, rural prevalence was comparatively lower (2.8\%) showing a stable to increasing trend [3]. Estimates from Ethiopia suggest that though HIV prevalence was higher in urban than rural areas, both areas showed a declining trend [4]. In Kenya, the urban and rural difference in HIV prevalence is becoming minimal [5].

India ranks third with respect to the number of people living with HIV/AIDS in the world [1]. The epidemic is concentrated among high-risk groups (HRGs), and over the last decade there has been a declining trend in the number of new infections [6]. The Indian government has made concerted efforts to reverse the HIV epidemic [7]. With more than $65 \%$ of India's population residing in rural areas [8], there have been reports of the HIV epidemic moving towards rural areas [9]. A community-based study in 2000 from Chennai, Tamil Nadu suggests that HIV prevalence is higher in urban than rural areas [10]. However, the National Family Health Survey, 2005-06 (NFHS-3) in Maharashtra state, and a population-based study from the state of Andhra Pradesh (2008), report that HIV prevalence is higher in rural than urban areas [11] [12]. While findings are mixed, it is imperative to understand the HIV scenario in urban and rural areas to improve the delivery of HIV prevention programs [13]. The national HIV estimation in India has used Spectrum software for rural-urban estimation, which combines the Spectrum and estimation package, and is globally recommended by UNAIDS [6] [14].

Though evidence suggests differences in HIV patterns in urban and rural populations in India, studies are limited to small geographic areas and the findings may not be generalizable. Further, national level urban-rural estimations have not been undertaken to date in India [6]. The objective of the study is to develop HIV estimation based on urban and rural adult populations in selected states of India to understand the difference in HIV related indices geographically.

\section{Methodology}

\subsection{Material and Procedures}

Based on reported HIV levels and trends of new infections, ten states of India have been selected for this study. Six states (Andhra Pradesh, Tamil Nadu, Karnataka, Maharashtra, Manipur and Nagaland) are high HIV prevalence states with declining new infections. Mizoram is a medium HIV prevalence state with stable new infections, while Punjab, Odisha and Jharkhand are low prevalence states that are showing increasing new infections in latest estimations [6]. Study period taken for analysis is 1981-2017. And this analysis was done from January 2013-Dec 2014.

\subsection{Data and Tools}

Data for the study were obtained from National AIDS Control Organization (NACO). The data used were Spectrum files and HIV Sentinel Surveillance (HSS) data for each state. Spectrum, version 4.53 beta 19, was used for estimations. This version includes the Estimation Projection Package (EPP) and AIDS Impact Module (AIM) 
inbuilt in Spectrum [15]. The detailed statistical methods of Spectrum is given elsewhere [6] [14]-[16] and appropriate input were given as needed to run the estimation. The Demproj module was used for demographic projections, based on population data, migration, mortality and fertility data [6]. The Spectrum files included information on the general population, HRGs and program statistics, including adult and child anti-retroviral therapy (ART) coverage, mother-to-child transmission of HIV (MTCT), treatment eligibility, and ratio of female-to-male HIV incidence (15 - 49 years). The age group for this analysis was taken as 15 - 49 years for all parameters, and the data are presented separately for each state. In addition, proportions were calculated and $\mathrm{z}$ tests conducted to test statistical significance.

\subsection{Epidemic Structure}

The concentrated epidemic type was selected in EPP. During HSS rounds, information on each participant's residence status (urban or rural) was collected. Urban and rural sub epidemic structures were separately configured for each state (Figure 1). The urban sub epidemic structure consisted of HRGs-injecting drug users, men who have sex with men, and female sex workers) —and low-risk groups (the remaining population) based on the data used in national estimation for each state [12]. All rural populations were considered to be low risk.

The population distribution for each sub-population group was calculated decadal-wise for the period 19812017 using published data [8] [17]. Assumptions on the duration of sexual behavior and the composition of the population were based on the last national estimations [6].

\subsection{Surveillance Data}

HSS data for HRGs and Integrated Bio-Behavioral Assessment data for HRGs, where available, were used [18] for projecting HRG curves. HSS data for antenatal care (ANC) was used for projecting the remaining population curves for urban areas and all population curves for rural areas. Though urban-rural analysis based on the location of HSS sites has been reported elsewhere [19] [20], these sites often do not fully represent the characteristics of these areas [21]-[23]. For this analysis we used the actual residence of clients recorded in the HSS ANC rounds, rather than sites designated as urban or rural sites, for projections of the HIV epidemic in India. HSS ANC sites, which included urban and rural data, with a minimum of 300 samples, were considered for analysis during national estimations. For this analysis any urban or rural locality HSS ANC data with a sample size of less than 100 was not included in the analysis.

\subsection{Curve Fitting and Fitting Results}

For each sub-population projection, the EPP classic model was used with 1900 iterations and 3000 resamples. Advance options were applied as appropriate. The best fitting curves of each HRG sub-population and the urban

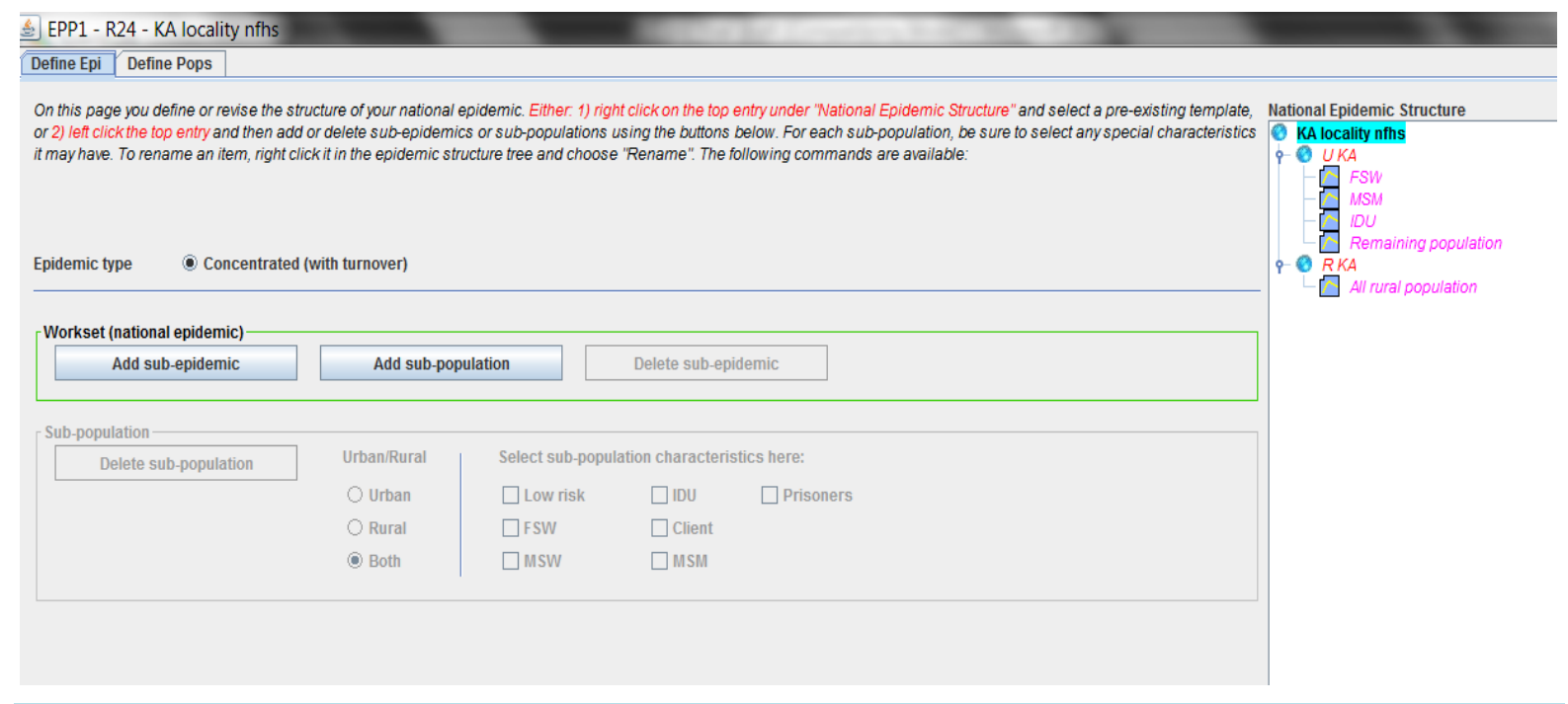

Figure 1. Epidemic structure in estimation and projection package in spectrum. 
general population were combined to produce the urban epidemic curve. The best fitting curve of the rural population was directly obtained.

\subsection{Calibration Factors}

Calibration for ANC sites was required to address the difference between ANC prevalence in population-based surveys and ANC positivity in HSS sites [24]. As this analysis required separate calibration factors for urban and rural ANC, two methods were used for calibration: 1) NFHS data for each state, where available, were considered; 2) for all other states, the calibration factor used in the latest round of HIV estimation was juxtaposed with the HSS ANC data for sites for three years (2005, 2006, and 2007).

\subsection{Ethical Approval}

The data sharing committee and Institutional Review Board of NACO, Ministry of Health and Family Welfare, Government of India approved the use of Spectrum and HSS data.

\subsection{Validation}

The parameters of curve fitting-1) start time of the epidemic; 2) force of infection; and 3) peak level of the epidemic curve-were kept on par with the national estimation values. The total number of adult rural and urban sub-populations was matched with the total population for each state. The infections and number of annual deaths were within the upper and lower bounds of the earlier published estimation data [6].

\section{Results}

\subsection{Current HIV Levels}

Table 1 presents urban-rural HIV prevalence among adults (15 - 49 years). Data indicate more than 1\% HIV positivity in population level HIV prevalence in Manipur state, urban Manipur, urban Nagaland and urban Mizoram. In urban Tamil Nadu and urban Maharashtra, HIV prevalence is lower than in the rural population, while in Karnataka HIV prevalence is similar for both urban and rural populations. In the remaining seven states, HIV prevalence is higher in the urban than the rural population. Apart from Karnataka, in all other states urban-rural differences in HIV prevalence were statistically significant ( $\mathrm{p} \leq 0.05)$.

Table 2 presents data on people living with HIV (PLHIV), new HIV infections and deaths among adult

Table 1. Adult (15 - 49 years) HIV prevalence among high-risk groups and the remaining population, selected states of India, 2011.

\begin{tabular}{|c|c|c|c|c|c|c|c|c|}
\hline \multirow[b]{2}{*}{ State } & \multicolumn{5}{|c|}{ Urban } & \multirow{2}{*}{$\begin{array}{c}\text { Rural } \\
\begin{array}{c}\text { All } \\
\text { population }\end{array}\end{array}$} & \multirow{2}{*}{$\begin{array}{c}\text { State } \\
\text { prevalence \% }\end{array}$} & \multirow{2}{*}{$\begin{array}{c}p \text { value, } 99 \% \\
\text { significance }\end{array}$} \\
\hline & IDU & MSM & FSW & $\begin{array}{l}\text { Remaining } \\
\text { population }\end{array}$ & $\begin{array}{c}\text { All } \\
\text { population }\end{array}$ & & & \\
\hline $\begin{array}{c}\text { Andhra } \\
\text { Pradesh [AP] }\end{array}$ & 5.63 & 15.51 & 8.18 & 0.73 & 0.83 & 0.76 & 0.78 & $<0.001$ \\
\hline Tamil Nadu [TN] & 7.90 & 2.68 & 2.79 & 0.16 & 0.17 & 0.32 & 0.25 & $<0.001$ \\
\hline Karnataka [KA] & 1.27 & 8.21 & 5.88 & 0.46 & 0.51 & 0.50 & 0.51 & $1.00^{\#}$ \\
\hline Maharashtra [MH] & 18.99 & 9.48 & 5.98 & 0.42 & 0.45 & 0.51 & 0.49 & $<0.001$ \\
\hline Manipur [MN] & 20.80 & 14.40 & 6.37 & 1.58 & 2.72 & 0.75 & 1.32 & $<0.001$ \\
\hline Nagaland [NG] & 1.91 & $\mathrm{NA}^{*}$ & 14.98 & 0.95 & 1.23 & 0.36 & 0.6 & $<0.001$ \\
\hline Mizoram [MZ] & 6.86 & NA & 4.31 & 0.82 & 1.16 & 0.31 & 0.75 & $<0.001$ \\
\hline Odisha [OD] & 7.72 & 4.98 & 2.34 & 0.35 & 0.36 & 0.27 & 0.29 & $<0.001$ \\
\hline Punjab [PJ] & 28.49 & 2.67 & 1.44 & 0.16 & 0.22 & 0.16 & 0.18 & $<0.001$ \\
\hline Jharkhand [JH] & 1.87 & NA & 1.03 & 0.37 & 0.37 & 0.11 & 0.18 & $<0.001$ \\
\hline
\end{tabular}

*NA: Not available, "-Not significant. IDU: Injecting Drug User, MSM: Men who have Sex with Men, FSW: Female Sex worker. 
Table 2. Number of people living with HIV, new HIV infections and deaths among people living with HIV (15 - 49 years) in selected states of India 2011: urban and rural differences.

\begin{tabular}{|c|c|c|c|c|c|c|c|c|c|}
\hline \multirow{2}{*}{ States } & \multicolumn{3}{|c|}{ Number of PLHIV } & \multicolumn{3}{|c|}{ Number of New HIV Infections } & \multicolumn{3}{|c|}{$\begin{array}{c}\text { Number of Deaths among } \\
\text { PLHIV }\end{array}$} \\
\hline & Urban & Rural & State Total & Urban & Rural & State Total & Urban & Rural & State Total \\
\hline Andhra Pradesh & 128,242 & 247,509 & 375,751 & 7273 & 14,036 & 21,309 & 8641 & 16,679 & 25,320 \\
\hline Tamil Nadu & 33,830 & 67,650 & 101,470 & 680 & 1370 & 2060 & 1830 & 3670 & 5500 \\
\hline Karnataka & 67,074 & 108,452 & 175,526 & 3091 & 4998 & 8089 & 4395 & 7106 & 11,501 \\
\hline Maharashtra & 132,336 & 180,124 & 312,461 & 6004 & 8335 & 14,340 & 7736 & 10,738 & 18,474 \\
\hline Manipur & 12,409 & 8671 & 21,080 & 662 & 462 & 1123 & 807 & 563 & 1370 \\
\hline Nagaland & 3824 & 3155 & 6980 & 153 & 126 & 279 & 294 & 242 & 536 \\
\hline Mizoram & 3824 & 969 & 4793 & 335 & 85 & 419 & 170 & 43 & 213 \\
\hline Odisha & 13,974 & 53,343 & 67,317 & 1086 & 4146 & 5233 & 976 & 3727 & 4703 \\
\hline Punjab & 12,688 & 16,072 & 28,759 & 1419 & 1797 & 3216 & 393 & 497 & 890 \\
\hline Jharkhand & 15,801 & 15,441 & 31,242 & 3025 & 2956 & 5982 & 530 & 518 & 1048 \\
\hline
\end{tabular}

PLHIV: People Living with HIV.

PLHIV (15 - 49 years) by urban-rural location in 2011. In the states of Andhra Pradesh, Tamil Nadu, Maharashtra, Odisha and Punjab, the number of PLHIVs, new infections and deaths was higher in rural than in urban populations.

\subsection{Trends in HIV Prevalence and Incidence: 2007-2011}

Table 3 presents a comparison of urban and rural HIV incidence in select states. Data indicate higher HIV incidence in rural Andhra Pradesh (more than 43 per 100,000 population new infections), followed by Manipur and Maharashtra (with 40 and 24 per 100,000 population new infections respectively). Among the urban population, HIV incidence was highest in Manipur (145 new infections per 100,000 population) followed by Mizoram and Jharkhand (102 and 71 per 100,000 population new infections respectively). Overall, Manipur, Mizoram and Andhra Pradesh had the highest number of new infections (73, 68 and 45 per 100,000 population new infections respectively) in 2011.

Figure 2 presents estimated trends in urban and rural HIV prevalence and incidence in the ten states from 1985-2015. As shown in the Figure, while the HIV epidemic started in the mid-1980s in the states of Andhra Pradesh, Tamil Nadu, Maharashtra, Karnataka, Manipur Nagaland and Punjab, in Mizoram, Odisha and Jharkhand, the epidemic started in the early 1990s mainly in the urban areas. The epidemic peaked at different times: Andhra Pradesh, Tamil Nadu, Karnataka and Nagaland show an early and lower peak for both prevalence and incidence in the urban compared to the rural population, while in Maharashtra, the rural peak was earlier and higher than the urban peak for both prevalence and incidence. Mizoram shows an earlier and lower peak in the rural than the urban population, while Manipur shows an earlier and higher urban peak as compared to the rural peak. In Odisha, both incidence and prevalence peaked earlier and were lower in the rural as compared to the urban population. HIV prevalence in urban Punjab is still peaking, while incidence was earlier and lower in rural Punjab. In Jharkhand both urban and rural HIV prevalence and incidence are still showing an increasing trend.

\section{Discussion}

This study explores for the first time differences in the urban and rural HIV epidemic in India. Two key findings emerge from the study. One, urban HIV prevalence and incidence are higher than rural HIV prevalence in all states other than Tamil Nadu and Maharashtra, although the number of PLHIV and the number of new infections remain higher in rural than urban areas in all states except Manipur, Mizoram, Nagaland and Jharkhand. Two, in all the states, except Jharkhand, the incidence of HIV is declining.

Our analysis suggests that in most states, the overall epidemic started showing an increasing trend around 
Table 3. Urban and rural HIV incidence by State, among adults (15 - 49 years) in selected states\#

\begin{tabular}{|c|c|c|c|c|}
\hline \multirow{2}{*}{ State/years } & \multicolumn{3}{|c|}{ HIV incidence (\%) } & \multirow[t]{2}{*}{$\begin{array}{c}\text { p value, } 99 \% \\
\text { significance }\end{array}$} \\
\hline & 2007 & 2009 & 2011 & \\
\hline Andhra Pradesh & 53.98 & 47.82 & 45.4 & \\
\hline Urban & 52.6 & 48.08 & 47.11 & \\
\hline Rural & 53.02 & 46.29 & 43.27 & $<0.001$ \\
\hline Tamil Nadu & 6.88 & 5.63 & 5.2 & \\
\hline Urban & 4.96 & 3.97 & 3.57 & \\
\hline Rural & 8.41 & 6.97 & 6.53 & $<0.001$ \\
\hline Karnataka & 33.02 & 26.93 & 24.10 & \\
\hline Urban & 28.66 & 24.97 & 23.61 & \\
\hline Rural & 34.54 & 27.18 & 23.55 & $<0.001$ \\
\hline Maharashtra & 30.05 & 25.49 & 23.44 & \\
\hline Urban & 28.59 & 23.81 & 21.41 & \\
\hline Rural & 29.95 & 25.77 & 24.09 & $<0.001$ \\
\hline Manipur & 88.98 & 81.94 & 73.46 & \\
\hline Urban & 170.03 & 159.63 & 145.23 & \\
\hline Rural & 51.23 & 46.16 & 40.72 & $<0.001$ \\
\hline Nagaland & 35.3 & 29.29 & 24.99 & \\
\hline Urban & 55.06 & 52.42 & 49.51 & \\
\hline Rural & 26.21 & 19.38 & 14.81 & $<0.001$ \\
\hline Mizoram & 77.61 & 72.53 & 68 & \\
\hline Urban & 110.05 & 106.60 & 102.28 & \\
\hline Rural & 37.34 & 31.28 & 27.2 & $<0.001$ \\
\hline Odisha & 32.49 & 26.02 & 22.91 & \\
\hline Urban & 31.88 & 28.63 & 28.48 & \\
\hline Rural & 31.81 & 24.87 & 21.25 & $<0.001$ \\
\hline Punjab & 20.74 & 20.08 & 21.02 & \\
\hline Urban & 20.99 & 21.81 & 24.67 & \\
\hline Rural & 19.97 & 18.45 & 18.22 & $<0.001$ \\
\hline Jharkhand & 21.23 & 26.98 & 34.76 & \\
\hline Urban & 43.93 & 55.80 & 71.76 & \\
\hline Rural & 13.3 & 16.92 & 21.81 & $<0.001$ \\
\hline
\end{tabular}

"Per 100,000 population.

1990; however, in Jharkhand and Orissa the epidemic started later (1995-2000). Overall, the epidemic is influenced by multiple factors. The different typologies of the virus that exist in India may have influenced the epidemic pattern [25]-[27], as HIV sub-typology has been associated with higher mucosal viral shedding, a surrogate marker of infectivity [28]. In addition, the epidemic curves may be influenced by the heterosexual transmission of HIV, particularly by female sex workers [29] in the majority of the states other than in north-east India, notably Manipur, where the epidemic is driven by injection drug use [30] [31]. Other population groups, like migrants, which were included in Odisha and Jharkhand, may have contributed to the HIV epidemic in these 
states [9] [32] [33]. In most states other than Mizoram, during the initial period, the growth of the epidemic has been relatively higher in urban than in rural areas.

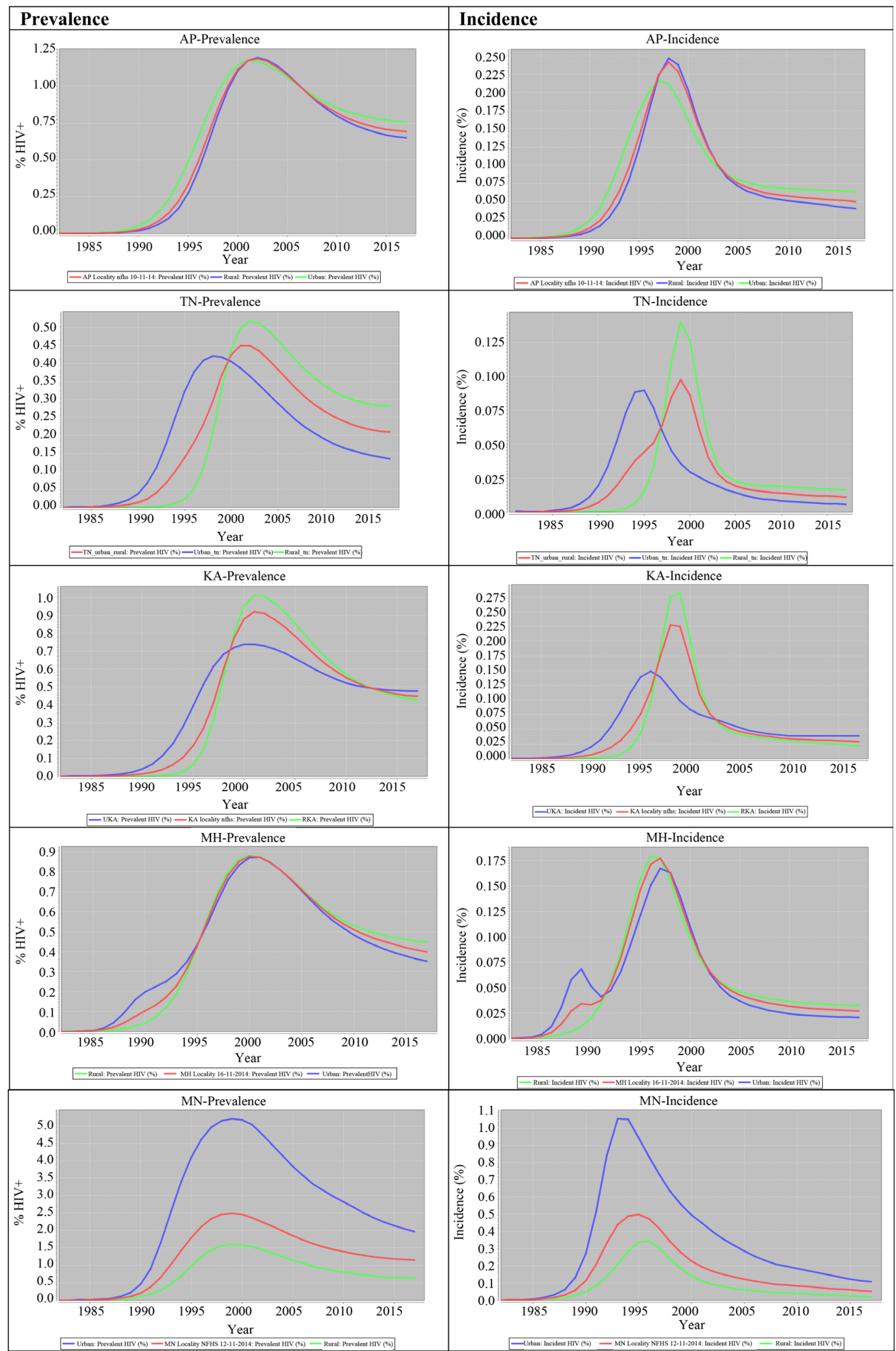



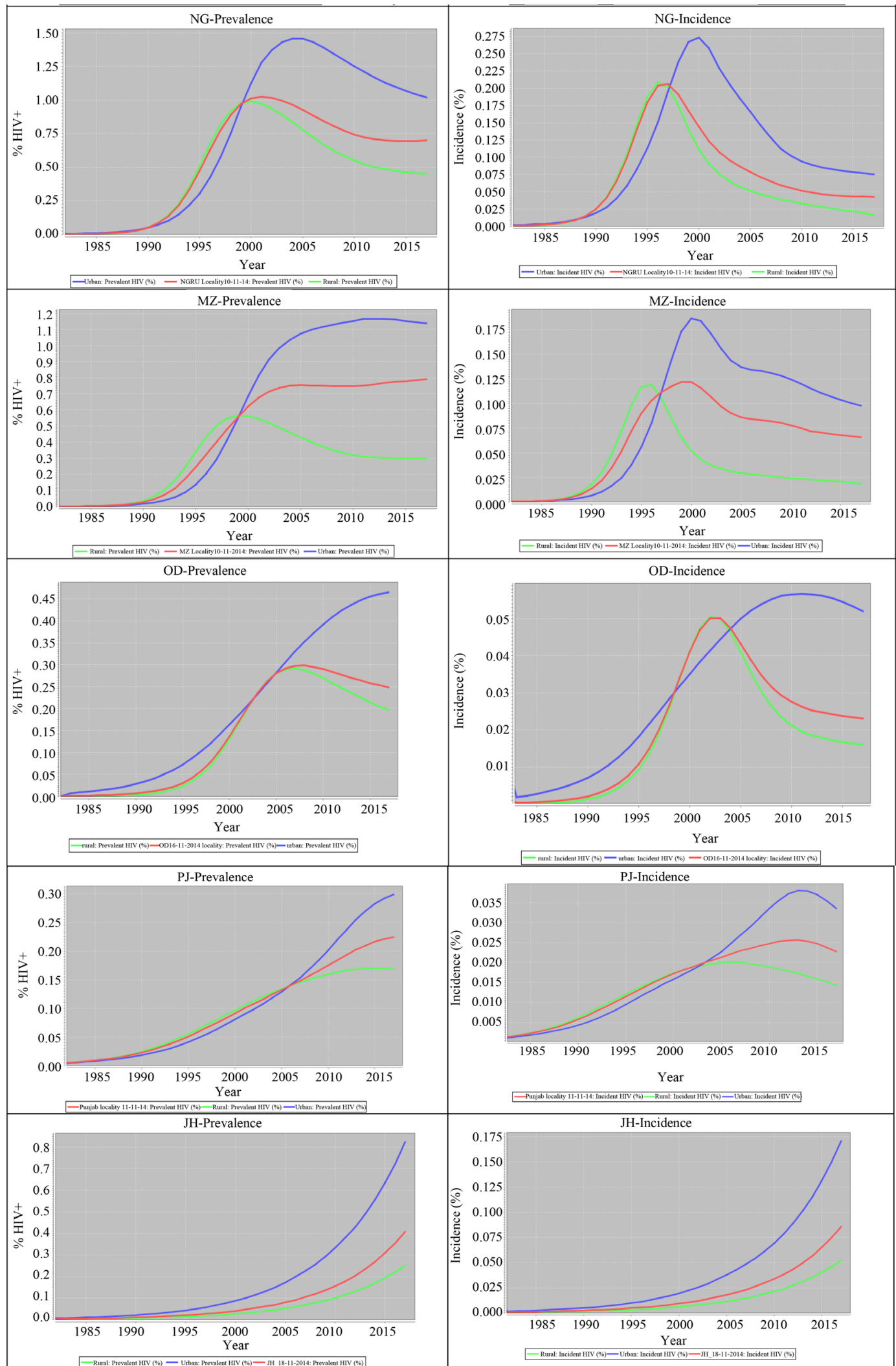

Figure 2. Comparison of urban and rural prevalence and incidence trends of HIV in selected states of India, 2011. 
In addition to the factors discussed above, the varying degrees of achievement of prevention and treatment interventions may have influenced HIV prevalence in the intervention era. Prevention programs like targeted interventions, with interpersonal communication and behavior change components, have been shown to either reduce or move the HIV prevalence curves downwards [34]-[36]. However, most of these programs were initially limited to urban areas and later expanded to selected districts in rural areas through the Link worker Scheme [37]. ART increases life expectancy, reduces mortality and reduces the HIV transmission rate [38] [39]. India's ART program started in 2004 with an initial focus on medical colleges and district hospitals in six high prevalence states, [40] [41] which were mostly in urban areas. These have been scaled up from 2008 not only in urban areas but also in rural areas in the form of Link ART centers [40]-[43]. However, the delay in covering the rural population with the same intensity as the urban population with these key interventions need to be taken in to consideration when discussing the higher number of PLHIV and number of new infections and deaths in rural areas in most states.

As the country is moving from prevalence-based epidemic tracking to number-based epidemic tracking [44], with one of the key indicators being reducing the number of annual new infections, the relatively high number of PLHIV and new infections in most states would need to be addressed. The size of the PLHIV population and the number of new infections provide an indication of the possible transmission networks that exist in the respective states. It is important to emphasize that HRGs' network size does influence epidemic patterns [45]-[48] and could at times explain the transmission of HIV to rural areas and to other low risk populations [47]-[50]. In addition, the issue of high HIV incidence, even in states that are showing a declining epidemic, needs to be considered as the dynamics and risk factors in rural areas are not only affected by migration [32] [51] but also by the interplay of local factors and networks such as sex work [46] [52]-[54]. These factors may have also contributed to HIV prevalence and new infections in the states of Karnataka and Tamil Nadu in particular, and to the overall epidemic in the rural areas of selected states [55].

The findings of this study need to be interpreted in light of certain limitations. The current estimation may have been influenced by the changing methodology in HSS for recruiting samples. Though migrants [32] and transgenders/Hijras are recognized as separate high-risk population group [56] adequate data were not available to add them in the current estimation. Information on size estimation of the HRG population in rural areas was not available; thus separate epidemic structures for rural HRGs and for the rural general population could not be created.

\section{Conclusion}

In short, our findings indicate lower levels of HIV prevalence and incidence in the urban population as compared to the rural population in Maharashtra and Tamil Nadu. In the remaining eight states, urban HIV prevalence and incidence are higher than rural prevalence and incidence. Future estimations of the HIV epidemic in the country need to adopt a similar approach to inform the design of appropriate state-level strategies for HIV prevention in urban and rural areas.

\section{Acknowledgements}

This paper (NACO/SIMU/NDAP/2015/05) was written as a part of the National Data Analysis Plan (NDAP), an initiative of the Strategic Information Management Unit of National AIDS Control Organization (NACO), Ministry of Health and Family Welfare, Government of India. We would like to thank the various divisions of NACO and State AIDS Control Societies (SACS) that have collected and maintained the program data. This paper was conceptualized, developed and finalized by the authors, under the guidance of mentors (senior public health experts) and the NDAP Unit, NACO. The Knowledge Network project of the Population Council, which is a grantee of the Bill \& Melinda Gates Foundation through Avahan, the India AIDS Initiative, has supported the scientific writing, reviewing, editing and finalization of this paper. This project is also supported by NACO's other development partners, which include Center for Diseases Control (CDC), World Health Organization-India, UNAIDS, FHI-360, and John Snow India. The views expressed in this paper are those of the authors, and do not necessarily reflect the views of NACO.

\section{References}

[1] Joint United Nations Program on HIV/AIDS (2014) The Gap Report. Geneva. 
[2] Joint United Nations Programme on HIV/AIDS (2014) The Cities Report. Geneva.

[3] Kayirangwa, E., Hanson, J., Munyakazi, L. and Kabeja, A. (2006) Current Trends in Rwanda’s HIV/AIDS Epidemic. Sexually Transmitted Infections, 82, i27-i31. http://dx.doi.org/10.1136/sti.2006.019588

[4] Ethiopian Health and Nutrition Research Institute (2012) HIV Related Estimates and Projections for Ethiopia—2012. Addis Ababa.

[5] National AIDS Control Council (2014) Kenya AIDS Response Progress Report 2014: Progress towards Zero.

[6] National Institute of Medical Statistics and National AIDS Control Organisation (2012) Technical Report India: HIV Estimates-2012. New Delhi.

[7] Sgaier, S.K., Claeson, M., Gilks, C., Ramesh, B.M., Ghys, P.D., Wadhwani, A., et al. (2012) Knowing Your HIV/ AIDS Epidemic and Tailoring an Effective Response: How Did India Do It? Sexually Transmitted Infections, 88, $240-$ 249. http://dx.doi.org/10.1136/sextrans-2011-050382

[8] Ministry of Home Affairs Government of India. Rural Urban Distribution of Population and Proportion of Rural and Urban Population-India/State/Union Teritory: Census 2011 (Provisional). Office of the Register General \& Census Commissioner, New Delhi.

[9] World Health Organisation (2005) Summary of Country profile for HIV/AIDS Treatment Scale-Up. http://dx.doi.org/10.1017/S0021932010000726

[10] Kang, G., Samuel, R., Vijayakumar, T.S., Selvi, S., Sridharan, G., Brown, D., et al. (2005) Community Prevalence of Antibodies to Human Immunodeficiency Virus in Rural and Urban Vellore, Tamil Nadu. The National Medical Journal of India, 18, 15-17.

[11] International Institute for Population Sciences and Macro International (2008) Maharastra: National Family Health Survey (NFHS-3), India 2005-06.

[12] Dandona, L., Dandona, R., Kumar, G.A., Reddy, G.B., Ameer, M.A., Ahmed, G.M., et al. (2008) Risk Factors Associated with HIV in a Population-Based Study in Andhra Pradesh State of India. International Journal of Epidemiology, 37, 1274-1286. http://dx.doi.org/10.1093/ije/dyn161

[13] Ramachandran, P. (2012) ICMR’s Tryst with HIV Epidemic in India: 1986-1991. Indian Journal of Medical Research, 136, 13-21.

[14] Stover, J., Brown, T. and Marston, M. (2012) Updates to the Spectrum/Estimation and Projection Package (EPP) Model to Estimate HIV Trends for Adults and Children. Sexually Transmitted Infections, 88, i11-i16. http://dx.doi.org/10.1136/sextrans-2012-050640

[15] Brown, T., Bao, L., Raftery, A.E., Salomon, J.A., Baggaley, R.F., Stover, J., et al. (2010) Modelling HIV Epidemics in the Antiretroviral Era: The UNAIDS Estimation and Projection Package 2009. Sexually Transmitted Infections, 86, ii3ii10. http://dx.doi.org/10.1136/sti.2010.044784

[16] Pandey, A., Sahu, D., Bakkali, T., Reddy, D., Venkatesh, S., Kant, S., et al. (2012) Estimate of HIV Prevalence and Number of People Living with HIV in India 2008-2009. BMJ Open, 2, Article ID: e000926. http://dx.doi.org/10.1136/bmjopen-2012-000926

[17] Kundu, A. (2006) Trends and Patterns of Urbanization and Their Economic Implications: India Infrastructure Report 2006.

[18] IBBA, India [Internet]. http://www.ibbainfo.in/

[19] Somi, G.R., Matee, M.I.N., Swai, R.O., Lyamuya, E.F., Killewo, J., Kwesigabo, G., et al. (2006) Estimating and Projecting HIV Prevalence and AIDS Deaths in Tanzania Using Antenatal Surveillance Data. BMC Public Health, 6, 120. http://dx.doi.org/10.1186/1471-2458-6-120

[20] NERCHA (2007) Swaziland HIV Estimates and Projections Workshop Report.

[21] National AIDS Control Organization and National Institute of Health and Family Welfare (2006) Annual Sentinel Surveillance for HIV Infection in India: Country Report 2004.

[22] Dandona, L., Lakshmi, V., Sudha, T., Kumar, G.A. and Dandona, R. (2006) A Population-Based Study of Human Immunodeficiency Virus in South India Reveals Major Differences from Sentinel Surveillance-Based Estimates. BMC Medicine, 4, 31. http://dx.doi.org/10.1186/1741-7015-4-31

[23] Kresge, K.J. (2007) IAVI-Report-11(4)-HIV Prevalence Estimates: Fact or Fiction.

[24] Gouws, E., Mishra, V. and Fowler, T.B. (2008) Comparison of Adult HIV Prevalence from National Population-Based Surveys and Antenatal Clinic Surveillance in Countries with Generalized Epidemics: Implications for Calibrating Surveillance Data. Sexually Transmitted Infections, 84, i17-i23. http://dx.doi.org/10.1136/sti.2008.030452

[25] Nelson, K.E., Costello, C., Suriyanon, V., Sennun, S. and Duerr, A. (2007) Survival of Blood Donors and Their Spouses with HIV-1 Subtype E (CRF01 A_E) Infection in Northern Thailand, 1992-2007. AIDS, 21, S47-S54. 
http://dx.doi.org/10.1097/01.aids.0000299410.37152.17

[26] Rangsin, R., Piyaraj, P., Sirisanthana, T., Sirisopana, N., Short, O. and Nelson, K.E. (2007) The Natural History of HIV-1 Subtype E Infection in Young Men in Thailand with up to 14 Years of Follow-Up. AIDS, 21, S39-S46. http://dx.doi.org/10.1097/01.aids.0000299409.29528.23

[27] Neogi, U., Bontell, I., Shet, A., De Costa, A., Gupta, S. and Diwan, V. (2012) Molecular Epidemiology of HIV-1 Subtypes in India: Origin and Evolutionary History of the Predominant Subtype C. PLoS ONE, 7, e39819. http://dx.doi.org/10.1371/journal.pone.0039819

[28] John-Stewart, G.C., Nduati, R.W., Rousseau, C.M., Mbori-Ngacha, D.A., Richardson, B.A., Rainwater, S., et al. (2005) Subtype C Is Associated with Increased Vaginal Shedding of HIV-1. The Journal of Infectious Diseases, 192, 492-496. http://dx.doi.org/10.1086/431514

[29] Gaffey, M.F., Venkatesh, S., Dhingra, N., Khera, A., Kumar, R., Arora, P., et al. (2011) Male Use of Female Sex Work in India: A Nationally Representative Behavioural Survey. PLoS ONE, 6, e22704. http://dx.doi.org/10.1371/journal.pone.0022704

[30] National AIDS Control Organisation (2007) Strategy and Implementation Plan: National AIDS Control Program PhaseIII [2006-2011].

[31] Sarkar, S., Das, N. Panda, S., Naik, T.N., Sarkar, K., Singh, B.C., Ralte, J.M., Aier, S.M. and Tripathy, S.P. (1993) Rapid Spread of HIV among Injecting Drug Users in North-Eastern States of India. Bulletin on Narcotics, 45, 91-105.

[32] Saggurti, N., Mahapatra, B., Sabarwal, S., Ghosh, S. and Johri, A. (2012) Male Out-Migration: A Factor for the Spread of HIV Infection among Married Men and Women in Rural India. PLoS ONE, 7, e43222. http://dx.doi.org/10.1371/journal.pone.0043222

[33] Dhapola, M., Sharan, M. and Shah, B. (2007) Migration, Youth and HIV Risk: A Study of Young Men in Rural Jharkhand. Economic and Political Weekly, 42, 40-47.

[34] Kumar, R., Jha, P., Arora, P., Mony, P., Bhatia, P., Millson, P., et al. (2006) Trends in HIV-1 in Young Adults in South India from 2000 to 2004: A Prevalence Study. Lancet, 367, 1164-1172. http://dx.doi.org/10.1016/S0140-6736(06)68435-3

[35] Kumar, R., Mehendale, S.M., Panda, S., Venkatesh, S., Lakshmi, P., Kaur, M., et al. (2011) Impact of Targeted Interventions on Heterosexual Transmission of HIV in India. BMC Public Health, 11, 549. http://dx.doi.org/10.1186/1471-2458-11-549

[36] Alary, M., Banandur, P., Rajaram, S.P., Thamattoor, U.K., Mainkar, M.K., Paranjape, R., et al. (2014) Increased HIV Prevention Program Coverage and Decline in HIV Prevalence among Female Sex Workers in South India. Sexually Transmitted Diseases, 41, 380-387. http://dx.doi.org/10.1097/olq.0000000000000138

[37] National AIDS Control Organization and National Institute of Health and Family Welfare (2009) Link Worker Scheme Operational Guidelines.

[38] Donnell, D., Baeten, J.M., Kiarie, J., Thomas, K., Stevens, W., Cohen, C.R., et al. (2010) Heterosexual HIV-1 Transmission after Initiation of Antiretroviral Therapy: A Prospective Cohort Analysis. The Lancet, 375, 2092-2098. http://dx.doi.org/10.1016/S0140-6736(10)60705-2

[39] Cohen, M.S., Chen, Y.Q., McCauley, M., Gamble, T., Hosseinipour, M.C., Kumarasamy, N., et al. (2011) Prevention of HIV-1 Infection with Early Antiretroviral Therapy. The New England Journal of Medicine, 365, 493-505. http://dx.doi.org/10.1056/NEJMoa1105243

[40] Department of AIDS Control (2009) Annual Report 2008-2009.

[41] National Institute of Health and Family Welfare and National AIDS Control Organization (2007) Annual HIV Sentinel Surveillance Country Report 2006.

[42] National AIDS Control Organization and National Institute of Health and Family Welfare (2010) Operational Guidelines Link ART Centre.

[43] Rewari, B. (2013) Indian Experience with Treatment as Prevention Key Approaches \& Challenges. 7th IAS Conference on HIV Pathogenesis, Treatment and Prevention, Kuala Lumpur, 30 June-3 July 2013. http://pag.ias2013.org/PAGMaterial/PPT/262_191/final.pptx

[44] Department of AIDS Control (2013) National AIDS Control Program Phase-IV (2012-2017) Strategy Document.

[45] Carnegie, N.B. and Morris, M. (2012) Size Matters: Concurrency and the Epidemic Potential of HIV in Small Networks. PLoS ONE, 7, e43048. http://dx.doi.org/10.1371/journal.pone.0043048

[46] Schneider, J.A., Saluja, G.S., Oruganti, G., Dass, S., Tolentino, J., Laumann, E.O., et al. (2007) HIV Infection Dynamics in Rural Andhra Pradesh South India: A Sexual-Network Analysis Exploratory Study. AIDS Care, 19, 1171-1176. http://dx.doi.org/10.1080/09540120701336392 
[47] Population Council (2007) Injecting Drug Users in India: Understanding Sexual Behaviour and Sexual Networks to Design Effective Behaviour Change Strategies.

[48] Medhi, G.K., Mahanta, J., Adhikary, R., Akoijam, B.S., Liegise, B., Sarathy, K., et al. (2011) Spatial Distribution and Characteristics of Injecting Drug Users (IDU) in Five Northeastern States of India. BMC Public Health, 11, 64. http://dx.doi.org/10.1186/1471-2458-11-64

[49] Potterat, J.J., Muth, S.Q., Rothenberg, R.B., Zimmerman-Rogers, H., Green, D.L., Taylor, J.E., et al. (2002) Sexual Network Structure as an Indicator of Epidemic Phase. Sexually Transmitted Infections, 78, i152-i158. http://dx.doi.org/10.1136/sti.78.suppl 1.i152

[50] Kohler, H. (2007) Sexual Network Structure and the Spread of HIV in Africa: Evidence from Likoma Island, Malawi. AIDS, 21, 2323-2332. http://dx.doi.org/10.1097/QAD.0b013e328285df98

[51] Rai, T., Lambert, H.S., Borquez, A.B., Saggurti, N., Mahapatra, B. and Ward, H. (2014) Circular Labor Migration and HIV in India: Exploring Heterogeneity in Bridge Populations Connecting Areas of High and Low HIV Infection Prevalence. The Journal of Infectious Diseases, 210, S556-S561. http://dx.doi.org/10.1093/infdis/jiu432

[52] Verma, R.K. and Collumbien, M. (2004) Homosexual Activity among Rural Indian Men: Implications for HIV Interventions. AIDS, 18, 1845-1847. http://dx.doi.org/10.1097/00002030-200409030-00014

[53] Becker, M.L., Ramesh, B.M., Washington, R.G., Halli, S., Blanchard, J.F. and Moses, S. (2007) Prevalence and Determinants of HIV Infection in South India: A Heterogeneous, Rural Epidemic. AIDS, 21, 739-747. http://dx.doi.org/10.1097/QAD.0b013e328012b885

[54] Banandur, P., Rajaram, S.P., Mahagaonkar, S.B., Bradley, J., Ramesh, B.M., Washington, R.G., et al. (2011) Heterogeneity of the HIV Epidemic in the General Population of Karnataka State, South India. BMC Public Health, 11, S13. http://dx.doi.org/10.1186/1471-2458-11-S6-S13

[55] Saggurti, N. and Malviya, A. (2009) HIV Transmission in Intimate Partner Relationships in India. India.

[56] National Institute of Epidemiology, Social and Rural Research Institute (IMRB) (2013) Technical Report Mapping and Size Estimation of Hijras and Other Transgender Populations in 17 States of India. 